\title{
O REGIME JURÍDICO E OS ASPECTOS PROCEDIMENTAIS DAS AUDIÊNCIAS PÚBLICAS EM SEDE DE CONTROLE CONCENTRADO DE CONSTITUCIONALIDADE NO BRASIL: ENTRE A PRETENSÃO DEMOCRÁTICA E A REALIDADE
}

\section{THE LEGAL REGIME AND PROCEDURAL ASPECTS OF PUBLIC HEARINGS IN CONCENTRATED CONTROL OF CONSTITUTIONALITY IN BRAZIL: BETWEEN DEMOCRATIC PROMOTION AND REALITY}

\section{Tainah Simões Sales ${ }^{1}$}

RESUMO: O artigo visa à análise dos aspectos formais das audiências públicas em sede de controle concentrado no Supremo Tribunal Federal a partir da sua criação, em 1999, até os dias atuais. Mediante pesquisa bibliográfica, descritiva, pura, e qualitativa, busca-se verificar a evolução e as deficiências do instituto quanto à pretensão de democratizar a jurisdição constitucional. Diante da necessidade da imagem de um Poder Judiciário legítimo e democrático, corroborada pela crise no sistema representativo, criou-se a ilusão de que as audiências públicas correspondem a uma efetiva participação social nos debates de relevância nacional, entretanto a realidade, do ponto de vista procedimental, se mostra diferente.

Palavras-chave: Audiências púlicas; participação popular; controle de constitucionalidade; jurisdição constitucional.

ABSTRACT: This paper aims to analyze the formal aspects of public hearings in the concentrated constitutional review in the Federal Supreme Court from its creation, in 1999, to the present day. Through bibliographical, descriptive, pure and qualitative research, we seek to verify the evolution and deficiencies of the institute regarding the pretension of democratizing the constitutional jurisdiction. Given the need for the image of a legitimate and democratic judiciary, corroborated by the crisis in the representative system, the illusion that public hearings correspond to an effective social participation in debates of national relevance was created, but the reality proves to be different.

${ }^{1}$ Doutora e Mestre pela Universidade Federal do Ceará. Realização de estágio doutoral (Doutorado Sanduíche PDSE/CAPES) na Aix-Marseille Université, França. Universidade de Fortaleza (Docente). E-mail: tainahsales@gmail.com. ORCID: https://orcid.org/0000-0002-6340-7428. 
Key-words: Public herings; popular participation; judicial reviwe; constitucional jurisdiction.

Sumário: 1. Introdução; 2. O advento das leis n. 9.868/99 e 9.882/99: previsão das audiências públicas no controle concentrado de constitucionalidade; 3. O regime jurídico das audiências públicas no âmbito do Supremo Tribunal Federal e seus aspectos procedimentais; 4. Considerações Finais; 5. Referências.

\section{INTRODUÇÃO}

O surgimento das audiências públicas, no Brasil, coincidiu com o momento de redemocratização, após o regime militar. O sucesso da utilização do instrumento no processo constituinte de 1987-1988 contribuiu para a sua consolidação na própria Constituição, no âmbito das atividades do Congresso Nacional, bem como nas legislações advindas logo após, que tratam dos processos nos órgãos da Administração Pública.

É possível afirmar que, no âmbito dos Poderes Legislativo e Executivo, desde o fim dos anos 80 e início dos anos 90, já era possível observar a previsão normativa e a realização das audiências públicas. A abertura para participação da população nos processos decisórios parecia ser mais bem aceita no âmbito dos poderes políticos, afinal, as principais autoridades são escolhidas pelo povo, tornando patente e justificável a necessidade de se estreitar as relações entre a sociedade e o poder público, no contexto de consolidação da Constituição Cidadã.

No Poder Judiciário, contudo, tal realidade foi vivenciada apenas em momento posterior. Isso porque, nas palavras de Roberto Baptista Dias, “[...] o Judiciário sempre foi considerado o mais hermético dos poderes" (DIAS, 2010, s/p). Não somente pelo fato de seus membros não serem eleitos pelo povo, mas também em razão da linguagem rebuscada e inacessível aos leigos, das vestimentas sóbrias dos magistrados e a forma de ingresso na carreira. Tudo isso corroborou o distanciamento entre os jurisdicionados e o Judiciário.

Assim, foi apenas em 1999, ou seja, mais de dez anos após o surgimento das 
audiências nos Poderes Executivo e Legislativo, que estas ganharam espaço no Poder Judiciário, mediante a promulgação da Lei n. 9.868/99 (que regulamenta a Ação Direta de Inconstitucionalidade, a Ação Declaratória de Constitucionalidade e a Ação Direta de Inconstitucionalidade por Omissão - esta última inserida apenas em 2009) e da Lei n. 9.882/99 (que prevê a Ação de Descumprimento de Preceito Fundamental). As referidas legislações regulamentam o controle de constitucionalidade concentrado no Brasil e permitem a realização das audiências no Supremo Tribunal Federal desde o seu texto original. Tais leis serão objeto de análise no presente trabalho.

A metodologia utilizada caracteriza-se como um estudo descritivo-analítico. O estudo será desenvolvido, quanto ao tipo, mediante pesquisa bibliográfica e documental, além de ser classificada como pura, qualitativa, descritiva e exploratória.

Tem-se como principal objetivo analisar os elementos formais (previstos na legislação e no Regimento Interno do Supremo Tribunal federal) que tratam da participação da sociedade nas audiências públicas em ações de controle concentrado julgadas pelo Supremo Tribunal Federal, para verificar se proporcionam, de modo efetivo, a ampliação das vozes no debate constitucional.

\section{O ADVENTO DAS LEIS N. 9.868/99 E 9.882/99: PREVISÃO DAS AUDIÊNCIAS PÚBLICAS NO CONTROLE CONCENTRADO DE CONSTITUCIONALIDADE}

Desde o advento das leis n. 9.868/99 e 9.882/99, foi possível perceber importante avanço no que tange à abertura de canais de diálogo com a sociedade no âmbito do Poder Judiciário, indo além da possibilidade de convocação pelo Supremo Tribunal Federal nas ações objetivas de controle. Vale citar as audiências públicas convocadas pelo Tribunal Superior Eleitoral (TSE) a respeito da 
normatização das eleições. Previstas desde 2009 na Lei n. 9.504/97 (em seu art. 105), são bastante utilizadas para legitimar o poder normativo atribuído à Justiça Eleitoral. Antes das deliberações e edições das resoluções que regulamentarão os detalhes do processo eleitoral, o TSE convoca lideranças partidárias, entidades que realizam pesquisas de opinião e outros interessados para debater pontos importantes sobre o tema.

Para as eleições de 2016, por exemplo, foram realizadas dez audiências públicas para discutir: modelos de lacres para as urnas eletrônicas, etiquetas de segurança e envelopes com lacres de segurança; escolha e registro de candidatos; representações, reclamações e pedidos de direito de resposta; pesquisas eleitorais; propaganda eleitoral, utilização e geração do horário gratuito e condutas ilícitas em campanha eleitoral; instalação de seções eleitorais especiais em estabelecimentos penais e em unidades de internação de adolescentes; arrecadação e gastos de recursos por partidos políticos e candidatos etc. (BRASIL, 2016, s/p).

Para o processo eleitoral de 2018, foram convocadas três audiências públicas, em que se discutiu: voto impresso; arrecadação, limite de gastos e prestação de contas; propaganda eleitoral, horário gratuito e condutas ilícitas; pesquisa eleitoral; representação, reclamação e direito de resposta e registro de candidatos (BRASIL, $2018, \mathrm{~s} / \mathrm{p})$.

No Conselho Nacional de Justiça (CNJ), a Resolução nº 67, de 3 de março de 2009, que aprovou o Regimento Interno do órgão, apresenta, em seu art. 26, o seguinte: “[...] o relator poderá, mediante despacho motivado, abrir período de consulta pública ou designar audiência pública para manifestação de terceiros, antes da decisão do pedido, se não houver prejuízo para o interessado" (BRASIL, 2009, p. 183). A Portaria n. 213/2013 regulamenta o instrumento (BRASIL, 2013, s/p). Desde então, foram realizadas cinco audiências, em que foram debatidos: eficiência da primeira instância e aperfeiçoamento legislativo voltado ao Poder Judiciário; novo Código de Processo Civil; permuta entre magistrados estaduais vinculados a 
Tribunais de Justiça de diferentes Estados da Federação; conciliação e mediação na Justiça do Trabalho e prestação jurisdicional na saúde. (BRASIL, 2019, s/p)

O Ato Regimental n. 1, de 2011, do Tribunal Superior do Trabalho, que alterou seu regimento interno para nele prevê-las e regulamentá-las; e o Código de Processo Civil, trazendo o $\S 2^{\circ}$ do art. 927, que trata dos processos de competência originária dos tribunais, com o seguinte teor: “[...] a alteração de tese jurídica adotada em enunciado de súmula ou em julgamento de casos repetitivos poderá ser precedida de audiências públicas e da participação de pessoas, órgãos ou entidades que possam contribuir para a rediscussão da tese"; bem como o art. 983, sobre o Incidente de Resolução de Demandas Repetitivas, que dispõe no $\S 1^{\text {o: }}$ "Para instruir o incidente, o relator poderá designar data para, em audiência pública, ouvir depoimentos de pessoas com experiência e conhecimento na matéria"; e o art. 1038, sobre o julgamento dos Recursos Especial e Extraordinário, também prevê o instrumento. (BRASIL, 2015, p.1).

A partir desses exemplos, verifica-se que o instituto já está disseminado também no Poder Judiciário. Diversos tribunais regionais e estaduais o utilizam, podendo-se citar o Tribunal de Justiça do Estado do Ceará, que realizou audiências sobre a nova Organização Judiciária do Estado, bem como sobre a judicialização da admissão de médicos sem processo seletivo nos quadros de cooperativa médica, entre outros. (CEARÁ, 2017, s/p).

Diversos autores comemoram a previsão legal das audiências públicas no Poder Judiciário, a partir de sua inclusão no controle concentrado desde 1999, destacando a pluralização do debate e a democratização do processo no âmbito do Supremo Tribunal Federal, como Gilmar Mendes, Uadi Bulos, Gustavo Binenbojm, entre outros. Os próprios ministros da Suprema Corte, quando a utilizam, exaltamna.

Não obstante tais entendimentos, considerando-as apenas em tese, percebe-se uma realidade que está longe de ser a desse instituto como instrumento plural e 
promotor da democracia no processo. Ao contrário, tal discurso torna as audiências públicas um verdadeiro fetiche: a decisão do Supremo torna-se legítima porque houve a realização da audiência pública, mesmo que os argumentos trazidos pela sociedade sequer tenham sido levados em consideração nas decisões da Corte. Exaltam-nas como se fossem suprir a falta de debate e de participação da sociedade na construção das decisões em matéria constitucional.

Com isso, não se afirma que as audiências são prejudiciais ou que devem ser extirpadas do ordenamento jurídico. Pelo contrário: concorda-se com os objetivos de sua criação, comemora-se a sua previsão nos mais diversos órgãos do Poder Judiciário, porém critica-se o discurso que a idealiza sem considerar a realidade.

Cria-se um paradigma científico, como explica Celso Campilongo (2000, p. 33), este sendo identificado "[...] a partir do momento em que é capaz de gerar um amplo consenso dentro da comunidade da qual ele surge". É o que acontece: perante a doutrina e a jurisprudência, é praticamente uníssono o discurso de que as audiências públicas são um importante instrumento de efetivação da participação da sociedade.

De acordo com a teoria das revoluções científicas de Thomas Kuhn (2011, $\mathrm{s} / \mathrm{p}$ ), a comunidade passa a realizar, assim, a chamada ciência normal. Pesquisam-se modos de ampliar o conhecimento acerca do paradigma eleito (no caso: as audiências públicas como elemento democratizante), mediante a harmonização da teoria e da abordagem de aspectos mais específicos e relevantes.

Inevitavelmente, dificuldades surgem e o paradigma atual parece não mais atender às necessidades daquele grupo. Os problemas ou anomalias fogem ao controle e resistem às soluções propostas pelo paradigma, desorientando a ciência normal, que passa por um período de crise. Quando isso ocorre, realizam-se estudos extraordinários, alheios à tradição das atividades da ciência normal.

Se o paradigma, de fato, ceder aos ataques crescentes das anomalias, os cientistas passam a conduzir suas pesquisas a novos compromissos, a novas bases, 
enfim, a um novo paradigma. Trata-se de uma etapa de conversão, em que os cientistas abandonam a posição em que se encontravam e vivenciam novas experiências a partir da atuação em torno do novo marco científico. Eis a constituição de uma revolução científica, que “[...] envolve uma transformação relativamente súbita e não estruturada na qual alguma parte do fluxo da experiência se rearranja de maneira diferente e exibe padrões que antes não eram visíveis" (KUHN, 2006, p. 28). É a tentativa deste trabalho: suscitar debates para que o paradigma das audiências públicas seja alterado.

Para concluir este tópico, importa reafirmar que a mera previsão do instituto na legislação ou mesmo a realização da audiência em sessão organizada pelo Supremo Tribunal Federal não são suficientes para consolidar o anseio da participação da sociedade na construção das decisões judiciais. Embora corresponda a um avanço (ao considerar que antes sequer havia essa possibilidade), não significa que há uma real democratização no processo. Esta só será verificada se os debates levantados pelos grupos que se manifestaram forem levados em consideração pelos ministros em seus votos. Com isso não se afirma que o voto estaria vinculado ao resultado da audiência, mas defende-se que o que foi dito pelos grupos deveria ser primordialmente considerado para a formulação do entendimento de cada julgador.

Neste artigo, porém, não será realizada uma análise pormenorizada dos votos. Por necessidade de corte epistemológico, o trabalho versará sobre os aspectos formais, previstos no ordenamento jurídico, envolvendo a participação da sociedade no âmbito das audiências públicas em controle concentrado de constitucionalidade, no intuito de verificar em que medida estes contribuem para uma efetiva democratização do processo constitucional.

\section{O REGIME JURÍDICO DAS AUDIÊNCIAS PÚBLICAS NO ÂMBITO DO $\begin{array}{llllll}\text { SUPREMO TRIBUNAL FEDERAL } & \text { E } & \text { SEUS ASPECTOS }\end{array}$ PROCEDIMENTAIS}


No âmbito do Supremo Tribunal Federal, as audiências públicas podem ser conceituadas, de acordo com Diogo Rais (2012, p. 48), como instrumento que permite à Corte a oitiva de pessoas especializadas em determinado tema ou dotadas de experiência na matéria para esclarecer questões ou circunstâncias de fatos de interesse público relevante ou com repercussão geral. Oportuniza-se o debate de público com pontos de vista e fundamentos diversos, além de promover a transparência e a publicidade do órgão. Ademais, têm a finalidade de buscar a aproximação da sociedade e do STF, pluralizando o processo constitucional e ampliando os olhares dos julgadores sobre a questão.

O autor destaca que seus efeitos diretos seriam: a) esclarecimento dos ministros acerca de circunstâncias de fato ou da complexidade da matéria (admitindo-se que, muitas vezes, as discussões transcendem o campo de conhecimento estritamente jurídico); b) oportunidade de discussões sobre teses opostas com fundamentos variados; c) ampliação e fomento do debate no interior da Corte; d) abertura e pluralidade do processo constitucional (no sentido proposto por Häberle de uma interpretação aberta do texto constitucional) (RAIS, 2012, p. 7374).

Além disso, cita como efeitos indiretos: a) ampliação e fomento do debate fora da Corte, a partir da disseminação das discussões por meio da imprensa e das mídias sociais; b) aproximação entre a sociedade e o Supremo Tribunal Federal, contribuindo para a diminuição da "barreira" entre os jurisdicionados e o Judiciário; c) aferição prévia da recepção da questão pela sociedade civil, realizando-se um prognóstico do comportamento social diante da decisão a ser tomada² .

2 Este último elemento deve ser analisado com cautela, na medida em que não se pode permitir que haja interferência direta da pressão popular na decisão dos ministros. Embora não se possa negar o caráter político da Suprema Corte, a pressão popular não pode ser elemento determinante do resultado do julgado, pois toda a legitimidade da jurisdição constitucional reside no fato de que o Poder Judiciário, por não ter membros eleitos pelo povo, poderá atuar 
A sua regulamentação perante a Suprema Corte está nas Leis n. 9.868/99 e 9.882/99, bem como na Emenda Regimental n. 29, de 2009, que alterou importantes dispositivos do Regimento Interno do STF (RISTF) (BRASIL, 2019, s/p). Inicialmente, far-se-á a análise das duas primeiras normas.

De acordo com o art. $6^{\circ}, \S 1^{\circ}$, da Lei n. ${ }^{\circ} 9.882 / 99^{3}$ (que dispõe apenas sobre a ADPF), o relator poderá convocar audiência pública sempre que entender necessário. Já de acordo com os arts. $9^{\circ}, \S 1^{\circ} ; 20$, § $1^{\circ}$, e 12-E, da Lei n. ${ }^{\circ} 9.868 / 99^{4}$ (que prevê os procedimentos da $\mathrm{ADI}$, da $\mathrm{ADC}$ e da $\mathrm{ADO}$ ), as audiências públicas poderão ser provocadas pelo ministro relator, sempre que: a) houver necessidade de esclarecimentos sobre determinada matéria e b) houver necessidade de esclarecimentos sobre circunstância de fato.

Quanto ao primeiro item, verifica-se a necessidade da oitiva do público em razão da complexidade da matéria, isto é, quando os conhecimentos técnicos da Corte forem insuficientes para a resolução da questão. Muitas vezes, as matérias constitucionais envolvem questões muito além das jurídicas, perpassando por temas da economia, política, ciências médicas, tecnologia, religião etc. Diante da

com maior liberdade na interpretação constitucional e poderá exercer seu papel contraminoritário na efetivação de direitos fundamentais.

3 ADPF (art. $6^{\circ}, \S 1^{\circ}$, Lei n. 9.882/99): “Se entender necessário, poderá o relator ouvir as partes nos processos que ensejaram a arguição, requisitar informações adicionais, designar perito ou comissão de peritos para que emita parecer sobre a questão, ou ainda, fixar data para declarações, em audiência pública, de pessoas com experiência e autoridade na matéria." (BRASIL, 1999, s/p).

4 ADI (art. $9^{\circ} \S 1^{\circ}$, Lei n. 9.868/99): "Em caso de necessidade de esclarecimento de matéria ou circunstância de fato ou de notória insuficiência das informações existentes nos autos, poderá o relator requisitar informações adicionais, designar perito ou comissão de peritos para que emita parecer sobre a questão, ou fixar data para, em audiência pública, ouvir depoimentos de pessoas com experiência e autoridade na matéria."; (BRASIL, 1999, s/p). ADC (art. 20. $\S 1^{\circ}$, Lei n. 9.868/99): "Em caso de necessidade de esclarecimento de matéria ou circunstância de fato ou de notória insuficiência das informações existentes nos autos, poderá o relator requisitar informações adicionais, designar perito ou comissão de peritos para que emita parecer sobre a questão ou fixar data para, em audiência pública, ouvir depoimentos de pessoas com experiência e autoridade na matéria."; e ADO (art. 12-E, caput, Lei n. 9.868/99): “Aplicam-se ao procedimento da ação direta de inconstitucionalidade por omissão, no que couber, as disposições constantes da Seção I do Capítulo II desta Lei." (BRASIL, 1999, s/p). 
inafastabilidade da jurisdição e do cumprimento do papel de guardião da Constituição, o STF precisará julgar assuntos que fogem da expertise dos ministros. Nesses casos, as audiências públicas ajudarão na formação do convencimento dos magistrados, oferecendo informações imprescindíveis para a prolação da decisão. Como exemplo, tem-se os julgamentos da ADPF n. 54 (aborto de fetos anencéfalos) e da ADI n. 3510 (células tronco embrionárias) cuja necessidade de conhecimentos médicos e biológicos eram patentes.

Em relação ao segundo item, pode-se afirmar que o interesse pela convocação do público se dará diante da inexistência de substratos fáticos suficientes para a formação do entendimento dos julgadores. A matéria em si não é necessariamente complexa, diferente do anterior. Aqui, o esclarecimento reside nas circunstâncias de fato.

Cabe ressaltar que, além das audiências públicas nas duas hipóteses mencionadas acima, o STF também poderá requisitar informações a entidades diversas ou peritos diante da sua insuficiência no processo. Não se trata, exatamente, de questão complexa ou cujo fato seja incerto, mas da ausência da informação necessária aos autos. Diante disso, o STF poderá requisitá-las àqueles que presumem tê-las, como entidades da Administração Pública, Ministérios, entre outros.

Não haverá necessidade de convocação de audiência pública para tanto. As requisições são feitas mediante ofício aos órgãos mencionados, e a resposta é dada de forma escrita, como foi o caso das ADIs 3.614 (2006) e 3.236 (2005) (RAIS, 2012, p. 51). Desse modo, as audiências não constituem a única forma de aquisição de informações e substratos para o julgamento dos ministros.

Além delas, há as requisições mencionadas no parágrafo acima, pareceres técnicos escritos e a figura do amicus curiae. Assim, é o caso concreto que indicará ao STF qual o mecanismo mais adequado à questão, diante da necessidade de se buscar obter informações e aparatos para a formação do convencimento. Não há, 
portanto, ordem de preferência ou indicação de hipóteses taxativas para utilização de cada um dos institutos. Inclusive, poderá a Corte fazer uso de mais de um mecanismo no mesmo processo. Neste trabalho, contudo, a análise se limita às audiências.

Sobre essas, importa mencionar que uma de suas marcas é a oralidade (RAIS, 2012, p. 51). A manifestação do amicus curiae, por exemplo, pode ser escrita, diferenciando-se do instituto ora em análise, cujo requisito de existência é a manifestação por viva voz.

Destaca-se que as convocações do público serão por meio de edital, que indicará a forma de inscrição e a data da realização da audiência. $\mathrm{O}$ art. $9^{\circ}$ da Lei n. 9.868/99, em seu $\S 3^{\circ}$, dispõe que o prazo entre a solicitação do relator e sua realização é de trinta dias, contudo se trata de prazo impróprio. Na prática, não há prazo mínimo ou máximo entre o edital de convocação e a sua realização de fato. Por exemplo, na ADI n. 3.510/07, o intervalo foi de quinze dias, mas, na ADPF n. 54, o lapso temporal foi de quase quatro anos.

De acordo com o expresso nas Leis 9.868/99 e 9.882/99, os aptos a depor são pessoas físicas ou representantes de pessoas jurídicas, associações, entidade de classe etc. dotadas de experiência ou conhecimento técnico ou fático sobre o assunto, não cabendo a participação de meros interessados (diferentemente do que ocorre em diversas audiências no âmbito da Administração Pública).

A partir da análise da referida legislação, afere-se que, quando foram criadas para o processo constitucional, as audiências possuíam a finalidade principal de instruir os julgadores. Seriam mais auxiliares da Corte, menos participantes do jogo democrático. Afinal, limitar as audiências para especialistas no assunto já contraria a concepção de pluralização do debate ou democratização do processo. Apenas uma pequena parcela poderá contribuir com o debate, embora toda a sociedade sofra os impactos dos julgamentos. Assim, resolveu-se priorizar os aspectos técnicos em detrimento do debate plural. 
Outro problema vivenciado pelos ministros foi a ausência de regulamentação do procedimento para a realização das audiências no STF. Isso porque, embora estivessem previstas em lei, não havia nenhuma norma que detalhasse as etapas de convocação, regras para sua realização etc. (DUARTE 2016, s/p). A primeira audiência, realizada em 20 de abril de 2007, no curso da ADI 3510 (sobre a constitucionalidade da Lei de Biossegurança), não tinha amparo em norma própria. Daí a necessidade de se utilizar as regras do Regimento Interno da Câmara dos Deputados por analogia. Nas palavras do ministro relator, Ayres Britto (STF, 2007, $\mathrm{s} / \mathrm{p})$ :

Diante dessa carência normativa, cumpre-me aceder a um parâmetro objetivo do procedimento de oitiva dos expertos sobre a matéria de fato da presente ação. E esse parâmetro não é outro senão o Regimento Interno da Câmara dos Deputados, no qual se encontram dispositivos que tratam da realização, justamente, de audiências públicas (arts. 255 usque 258 do RI/CD). Logo, são esses os textos normativos de que me valerei para presidir os trabalhos da audiência pública a que me propus.

Entretanto tal cenário foi modificado com o passar do tempo, sobretudo mediante o advento da Emenda Regimental n. 29, de 11 de fevereiro de 2009, que alterou os artigos 13, 21, 154 e 363 do Regimento Interno da Suprema Corte, quando as audiências públicas ganharam nova dimensão, novo alcance: de mero mecanismo de informação, passaram a ser importante mecanismo de aproximação entre a sociedade civil e o STF.

Atualmente, é possível perceber quatro perfis de audiências: aquelas voltadas apenas para esclarecimentos de caráter técnico (como nos casos da ADI 3.510, ADPF 101 e ADI 4.679); as que objetivam o estabelecimento de um diálogo social no STF (ADPF 186, por exemplo); as que combinam os dois perfis anteriores (v. ADI 4.650 e ADPF 54); e as que buscam estabelecer um diálogo institucional relacionado a políticas públicas (como no caso da judicialização da saúde, desvinculada de processo específico).

Corroboraram essa nova visão as gravações das sessões da Corte, que passaram a ser televisionadas, além da Rádio Justiça, dos canais oficiais de 
divulgação de vídeos e das redes sociais (RAIS, 2012, p. 57). Desse modo, a tímida previsão na legislação do controle concentrado foi complementada pela referida norma regimental, não sendo mais necessária a utilização do modelo previsto para o processo legislativo de forma subsidiária.

De acordo com as Leis 9.868/99 e 9.882/99, caberia apenas ao ministro relator convocar a audiência, no âmbito das ações objetivas de controle de constitucionalidade. Entretanto, a partir de 2009, a Emenda passou a regulamentar a audiência pública jurisdicional e ampliou as oportunidades de sua utilização, ao dispor sobre a possibilidade de convocação pelo presidente do Supremo ${ }^{5}$ não apenas no curso das ações de controle direto de constitucionalidade (como era previsto até então, pelas referidas leis), mas sempre que entender necessário para a resolução de questões de repercussão geral e de interesse público relevante ${ }^{6}$, ainda que no âmbito de processos de cunho subjetivo. Assim, tanto foi ampliada legitimidade para convocação como os casos em que pode ser utilizada.

Questionamento relevante pode ser feito: diante da convocação pelo presidente da Corte da não concordância pelo ministro relator, qual entendimento deve prevalecer? Para responder a esta pergunta, deve-se analisar os dois dispositivos que tratam do tema.

Conforme exposto no art. 13, XVII, do RISTF (BRASIL, 2007, s/p), caberá ao presidente convocá-la "para ouvir o depoimento de pessoas com experiência e autoridade em determinada matéria, sempre que entender necessário o esclarecimento de questões ou circunstâncias de fato, com repercussão geral e de interesse público relevante, debatidas no âmbito do Tribunal”.(BRASIL, 2019, p.

5 Neste trabalho, o enfoque será, contudo, as ações objetivas de controle de constitucionalidade, conforme já esclarecido anteriormente.

6 Dispõe o art. 13 do referido Regimento: "São atribuições do presidente: [...] XVII - convocar audiência pública para ouvir o depoimento de pessoas com experiência e autoridade em determinada matéria, sempre que entender necessário o esclarecimento de questões ou circunstâncias de fato, com repercussão geral e de interesse público relevante, debatidas no âmbito do Tribunal”. (BRASIL, 2007, s/p). 
31.)

Ademais, conforme o exposto no art. 21, XVII, é de competência do relator “[...] convocar audiência pública para ouvir o depoimento de pessoas com experiência e autoridade em determinada matéria, sempre que entender necessário o esclarecimento de questões ou circunstâncias de fato, com repercussão geral ou de interesse público relevante" (BRASIL, 2007, s/p).

Analisando os dois dispositivos, verifica-se que a única diferença é que o primeiro se refere a "questões debatidas no âmbito do Tribunal". A partir de tal expressão, pode-se aferir que o presidente poderá convocar audiências quando relevante à Corte, enquanto o relator poderá convocar quando relevante ao processo. O presidente poderá promover audiências públicas inclusive desvinculadas de processo (como foi o caso da audiência sobre a judicialização da saúde), alternativa não possível ao ministro relator. Assim, a priori, não haveria conflito entre a concordância ou não sobre a sua realização, pois são órbitas de atuação diferentes (RAIS, 2012, p. 59).

Outro ponto que merece destaque são os requisitos da repercussão geral ou interesse público relevante. Surgiram para evitar a banalização do instituto, de modo que somente serão utilizadas quando o interesse transcender os direitos subjetivos das partes do processo. No âmbito das ações principais de controle, como se tratam de processos objetivos e abstratos, sem partes e sem direitos subjetivos diretos a serem discutidos, tais requisitos tornam-se, de certa forma, redundantes, mas não se pode esquecer que a Emenda proporcionou a abertura das audiências para outros processos, inclusive de cunho subjetivo. Daí a demonstração dos requisitos da repercussão geral ou interesse público relevante para a sua convocação. Quanto ao procedimento, deve-se observar o disposto no art. 154 do RISTF:

I - o despacho que a convocar será amplamente divulgado e fixará prazo para a indicação das pessoas a serem ouvidas;

II - havendo defensores e opositores relativamente à matéria objeto da audiência, será garantida a participação das diversas correntes de opinião; 
III - caberá ao ministro que presidir a audiência pública selecionar as pessoas que serão ouvidas, divulgar a lista dos habilitados, determinando a ordem dos trabalhos e fixando o tempo que cada um disporá para se manifestar;

IV - o depoente deverá limitar-se ao tema ou questão em debate;

V - a audiência pública será transmitida pela TV Justiça e pela Rádio Justiça;

VI - os trabalhos da audiência pública serão registrados e juntados aos autos do processo, quando for o caso, ou arquivados no âmbito da Presidência;

VII - os casos omissos serão resolvidos pelo ministro que convocar a audiência. (BRASIL, 2007, p. 84).

Em relação ao inciso I, a partir da análise das audiências já realizadas, é possível afirmar que são três as modalidades de indicação de participantes: a) convite, por meio de ofício expedido pelo ministro presidente da audiência pública; b) indicação de expositores pelos participantes do processo (como amigos da Corte, Procurador Geral da República, parte autora etc.) e c) inscrição aberta ao público, por meio de publicação de edital de convocação geral (LEITE, 2015, p. 493). Neste último caso, a publicidade não deve se limitar apenas ao Diário Oficial. A ampla divulgação em redes sociais, sites, televisão, rádio e outros é imprescindível para que o maior número de pessoas possa ter conhecimento e possa se inscrever.

Sobre o II, destaca-se a consagração do princípio do contraditório, determinando a paridade nas manifestações no caso de divergências sobre o tema, de modo que se torne possível a pluralização do debate e a oitiva de diferentes grupos, com diferentes pontos de vista e fundamentos a respeito da questão. Embora o texto mencione apenas "defensores e opositores", dividindo os participantes em apenas dois grupos, a interpretação deve ser no sentido de albergar diferentes correntes, podendo ser mais que dois grupos. A lógica binária do processo civil deve ser relativizada quando o objetivo é ampliar as vozes do debate e proporcionar a inclusão do maior número possível de pontos de vista sobre a questão.

O inciso III se justifica em razão das limitações de tempo e espaço. Entretanto, se, por um lado, deve-se ter em mente que a audiência gera custos, estrutura, tempo dos servidores e dos ministros, por outro lado não se pode esquecer 
a essência do instituto, que é a possibilidade de oportunizar à sociedade a voz em temas sobre os quais tem conhecimento e dos quais sofrerão as consequências da decisão. Daí porque o ministro deve ter cautela nesta fase de habilitação e estabelecer os critérios de seleção. A exclusão de candidato deve ser amplamente motivada, para que seja assegurada a lisura no procedimento e seja permitido o controle e até mesmo a revisão da decisão da seleção dos participantes.

Ressalta-se que não há regras pré-definidas acerca da seleção dos candidatos. Estas serão determinadas pelo relator (RAIS, 2012, p. 68). A título de exemplo, na primeira audiência realizada (nos autos da ADI 3.510, sobre a Lei de Biossegurança, em 2007), apenas os expositores indicados na petição inicial, pelo presidente da República e pelos amici curiarum foram convidados pelo ministro relator. Na segunda (ADPF n. 101, sobre importação de pneus usados, em 2008), foi realizado sorteio entre os indicados pelos participantes do processo. $\mathrm{Na}$ terceira (ADPF n. 54, sobre aborto dos fetos anencéfalos), tanto houve convite de ofício a entidades por parte do relator como houve o deferimento e o indeferimento de grupos que manifestaram interesse em participar.

A quarta, a quinta e a sexta audiências, já sob a vigência da ER 29/09, que trataram, respectivamente, sobre a judicialização da saúde sem vinculação a processo objetivo, sobre as cotas raciais nas universidades (ADPF n. 186) e sobre a Lei Seca (ADI n. 4.103), determinaram que os interessados devessem enviar os dados dos representantes que iriam expor, além do resumo da tese, a fim que fosse possível a escolha pelo relator (RAIS, 2012, p. 68).

Critica-se esta "escolha" e a ausência de parâmetros pré-definidos para seleção dos candidatos, pois se torna paradoxal haver a previsão de um instrumento com o intuito de democratizar o processo e pluralizar o debate em que a participação da sociedade fica sujeita a uma decisão discricionária do relator, sobre a qual nem cabe recurso.

Quanto ao item IV, a sua justificativa reside na necessidade de se garantir a 
eficiência do instituto e evitar que as discussões fujam das suas finalidades. Trata-se da regra que busca preservar as audiências e evitar a sua deturpação.

Sobre o inciso V, destaca-se a atenção para a transparência e a publicidade que devem ser garantidas no intuito de que a sociedade civil tome conhecimento do que fora discutido e possa se apropriar das informações divulgadas. Ressalta-se, ainda, que esta previsão não impede o Supremo Tribunal Federal de permitir que a imprensa em geral esteja presente para transmitir a audiência. Desde a primeira realizada, é comum a abertura para a mídia, tendo sido estabelecidas regras para o credenciamento das instituições interessadas em realizar a cobertura.

Já o item VI trata da regra que determina o registro e o arquivamento da audiência, garantindo a sua perenidade. O conteúdo discutido deve estar acessível à população em geral. Quando estiver vinculada a um processo, os registros serão juntados aos autos. Quando decorrer de debates da Corte que não tenham vinculação a processos específicos, serão arquivados pela Presidência para permitir a posterior consulta. Entretanto houve omissão sobre como deverão ser esses registros. Na prática, há a transcrição das falas de todos os participantes do ato.

$\mathrm{O}$ último inciso permite a flexibilidade das regras de procedimento das audiências, na medida em que oportuniza ao relator ou ao presidente do Tribunal a resolução dos casos omissos, conforme a circunstância. Como não há regras detalhadas sobre sua estrutura e sua organização (por exemplo, não há o estabelecimento de critérios de seleção na fase de habilitação dos candidatos), o desenvolvimento delas dependerá bastante de como o ministro que convocar irá conduzir, abrindo margem, inclusive, para certas arbitrariedades (o que contraria o potencial democrático do instituto).

Um dos problemas desta regra é a ausência de previsão de recurso em face das decisões do ministro acerca do procedimento a ser adotado na audiência, o que acaba permitindo poder exacerbado ao ministro que a convocar e, inevitavelmente, escolhas arbitrárias que poderão ter forte impacto no conteúdo que será debatido 
pelos participantes.

Ademais, há de se ressaltar que não há regras relativas à determinação da regularidade para acontecerem. Em geral, os ministros não assistem às audiências e estas são realizadas em caráter excepcional e esporádico.

Até a data de 22 de julho de 2019, foram realizadas, no total, 26 (vinte e seis) audiências públicas pela Suprema Corte brasileira (BRASIL, 2019, s/p). A primeira audiência pública foi realizada em 2007, isto é, mais de sete anos após o seu surgimento. Considerando que a sua criação ocorreu em novembro de 1999 (por meio da promulgação da Lei n. 9.868/99, conforme já afirmado anteriormente), tem-se uma média de pouco mais de 1 audiência por ano (para ser mais exata: 1,3). Trata-se de número ínfimo, considerando que o STF julga, anualmente, centenas de ações.

Somente em 2018, para se ter uma ideia, a Corte prolatou 305 (trezentas e cinco) decisões em plenário em ações de controle concentrado (ADI, ADC, ADO e ADPF) (BRASIL, 2019, s/p). Somando às decisões colegiadas recursais e de outros processos originários, o número chega a 3.272 (três mil, duzentos e setenta e dois). Sabe-se que nem todos os processos são de relevância social suficiente para justificar a necessidade de audiência pública, mas, de qualquer forma, os números demonstram grande disparidade entre o número de decisões prolatadas pelo plenário e o número de audiências realizadas.

Outro dado importante diz respeito ao fato de que, entre 2010 e 2017, o STF julgou, no mérito, 395 (trezentos e noventa e cinco) ações diretas de inconstitucionalidade (desconsiderando, portanto, as outras ações de controle concentrado, quais sejam, ADC, ADO e ADPF) (BRASIL, 2018, s/p). E, destas, apenas 8 (oito) contaram com a realização de audiências públicas, o que corresponde a apenas 2\%. A partir de tais dados, infere-se que o STF atribui relevância reduzida às audiências. 


\section{CONSIDERAÇÕES FINAIS}

Como resultado parcial obtido, é possível afirmar que as audiências públicas são, muito mais, mecanismos de pretensão democrática que mecanismos democráticos de fato. Trata-se de um procedimento formal que sofistica e dá uma resposta imediata para os anseios de democratização do processo, mas que, na prática, não representa participação ativa da sociedade.

Alguns elementos formais evidenciam isto: a baixa frequência com que acontecem; a iniciativa continua muito vinculada à discricionariedade do relator, mesmo após a sua regulamentação pela Emenda Regimental n. 29/09, abrindo margem para arbitrariedades; não há transparência quanto à definição do rito, dos critérios de admissão dos participantes e motivação dos indeferimentos; não há previsão de recursos em caso de indeferimento; entre outras questões.

Com um olhar crítico, Carolina Vestena afirma que a participação social nesses julgamentos é secundária e a democratização desses processos não é verificada efetivamente. Em suas palavras, as audiências são realizadas seguindo uma

[...] lógica de reprodução do formalismo intrínseco às instituições judiciais e promovem uma cena ilusória que leva à crença de que todos os indivíduos e grupos interessados poderiam intervir paritariamente na interpretação da Constituição. (VESTENA, 2010, p. 103).

Se é possível afirmar que as audiências promovem a abertura do STF à sociedade em um novo paradigma, por outro lado, as formas tradicionais de condução instrutória das audiências e de decidir parecem inalteradas (GODOY, 2017, p. 204-205). Continua havendo a prevalência de "saberes enciclopédicos" de cada ministro, em detrimento da construção de uma decisão coletiva. Nem mesmo a introdução das audiências públicas parece ter retirado esse caráter, resultando em um acórdão em que há mera soma de votos individuais dos magistrados. A fase 
decisional não alberga um engajamento colegiado, pois cada um continua votando à sua maneira. No mesmo sentido, destaca Miguel Godoy: “[...] o modelo decisório do STF não é de uma decisão da corte (per curiam), mas sim o de decisões fracionárias individuais" (GODOY, 2017, p. 204-205).

Assim, de acordo com a presente pesquisa, diante do modo pelo qual as audiências vêm sendo desenvolvidas e diante da regulamentação atual do instituto, não é possível aferir que elas são, efetivamente, elementos democratizadores do processo. Há apenas uma pretensão ou um discurso simbólico neste sentido, embora seja reconhecido o avanço, considerando que antes de 1999 sequer eram previstas.

\section{REFERÊNCIAS}

BRASIL. Assessoria Consultiva do Tribunal Superior Eleitoral. Audiências públicas. Portal TSE, Brasília, 14 jul. 2016. Disponível em: http://www.tse.jus.br/eleitor-e-eleicoes/eleicoes/eleicoes-anteriores/eleicoes2016/area-juridica/audiencias-publicas-eleicoes-2016. Acesso em: 3 abr. 2019.

BRASIL. Assessoria Consultiva do Tribunal Superior Eleitoral. Audiências públicas para as Eleições 2018. Portal TSE, Brasília, 17 set. 2018. Disponível em: http://www.tse.jus.br/eleitor-e-eleicoes/eleicoes/eleicoes-2018/audiencias-publicas. Acesso em: 3 abr. 2019.

BRASIL. Conselho Nacional de Justiça. Audiências públicas. Brasília: CNJ, [2017]. Disponível em: http://www.cnj.jus.br/programas-e-acoes/audienciaspublicas. Acesso em: 3 abr. 2019.

BRASIL. Conselho Nacional de Justiça. Portaria ${ }^{\circ} 213$, de 29 de novembro de 2013. Regulamenta as audiências públicas no Conselho Nacional de Justiça. Diário da justiça Eletrônico, Brasília, DF, 2 dez. 2013. Disponível em: http://www.cnj.jus.br/busca-atos-adm?documento= 112. Acesso em: 15 jan. 2019.

BRASIL. Conselho Nacional de Justiça. Resolução nº 67, de 3 de março de 2009. Aprova o Regimento Interno do Conselho Nacional de Justiça e dá outras providências. Diário Oficial da União [da] República Federativa do Brasil: 
seção 1, Brasília, DF, ano 146, n. 44, p. 183, 6 mar. 2009. Disponível em: http://www.cnj.jus.br/atos-normativos?documento=124. Acesso em: 15 jan. 2019.

BRASIL. Lei no 13.105, de 16 de março de 2015. Código de Processo Civil. Diário Oficial da União [da] República Federativa do Brasil: seção 1, Brasília, DF, ano 152, n. 51, p. 1, 17 mar. 2015. Disponível em: http://www.planalto.gov.br/ccivil_03/_ato2015-2018/2015/lei/113105.htm. Acesso em: 15 jan. 2019.

BRASIL. Lei $\mathrm{n}^{\circ}$ 9.868, de 10 de novembro de 1999. Dispõe sobre o processo e julgamento da ação direta de inconstitucionalidade e da ação declaratória de constitucionalidade perante o Supremo Tribunal Federal. Diário Oficial [da] República Federativa do Brasil: seção 1, Brasília, DF, ano 137, n. 216, p. 1, 11 nov. 1999b. Disponível em: http://www.planalto.gov.br/ccivil_03/LEIS/L9868.htm. Acesso em: 15 jan. 2019.

BRASIL. Lei $\mathrm{n}^{\circ}$ 9.882, de 3 de dezembro de 1999. Dispõe sobre o processo e julgamento da argüição de descumprimento de preceito fundamental, nos termos do $\S 1^{\circ}$ do art. 102 da Constituição Federal. Diário Oficial [da] República Federativa do Brasil: seção 1, Brasília, DF, ano 137, n. 232, p. 2, 6 dez. 1999c. Disponível em: http://www.planalto.gov.br/ccivil_03/leis/19882.htm. Acesso em: 15 jan. 2019.

BRASIL. Supremo Tribunal Federal. Audiências públicas realizadas. Portal STF, Brasília, 25 jun. 2019a. Disponível em: http://www.stf.jus.br/portal/audienciaPublica/audienciaPublica.asp?tipo=realizada. Acesso em: 11 jan. 2019.

BRASIL. Supremo Tribunal Federal. Regimento interno. Brasília: STF, Secretaria de Documentação, 2019b. Disponível em: http://www.stf.jus.br/arquivo/cms/legislacaoRegimentoInterno/anexo/RISTF_ER_5 1_web.old.pdf. Acesso em: 20 jul. 2019.

BRASIL. Supremo Tribunal Federal. Secretaria de Gestão Estratégica. Decisões colegiadas - Plenário. Portal STF, Brasília, 4 set. 2018c. Disponível em: http://portal.stf.jus.br/textos/verTexto.asp?servico=estatistica\& pagina $=$ decisoesplenario. Acesso em: 11 jan. 2019.

CAMPILONGO, Celso Fernandes. O direito na sociedade complexa. São Paulo: Max Limonad, 2000.

CEARÁ. Tribunal de Justiça do Estado do Ceará. Audiência pública debate projeto de lei do TJCE que trata da nova Organização Judiciária do Estado. Notícias do 
TJCE, Fortaleza, 19 set. 2017b. Disponível em: https://www.tjce.jus.br/noticias/audiencia-publica-debate-projeto-de-lei-do-tjceque-trata-da-nova-organizacao-judiciaria-do-estado/. Acesso em: 22 jul. 2019.

CEARÁ. Tribunal de Justiça do Estado do Ceará. Audiência pública debate admissão de médicos em cooperativas de saúde. Notícias do TJCE, Fortaleza, 7 ago. 2017a. Disponível em: https://www.tjce.jus.br/noticias/audiencia-publica-notjce-debate-admissao-de-medicos-em-cooperativas-de-saude/. Acesso em: 22 jul. 2019.

CONSULTOR JURÍDICO. Anuário da Justiça Brasil 2018. São Paulo: CONJUR, 2018.

DIAS, Roberto. Supremo na redoma. Estadão, São Paulo, 11 set. 2010. Disponível em: http://alias.estadao.com.br/noticias/geral,supremo-na-redoma,608464. Acesso em: 27 mar. 2019.

DUARTE, Ricardo Cesar. A utilização das audiências públicas no Poder Judiciário: o caso da efetivação das políticas públicas de saúde. Orientador: Antonio Rodrigues de Freitas Júnior. 2016. 102 f. Dissertação (Mestrado em Direitos Humanos) - Universidade de São Paulo, São Paulo, 2016. Disponível em: http://www.teses.usp.br/teses/disponiveis/2/2140/tde-18082016

150721/publico/RicardoAudienciasIntegral.pdf. Acesso em: 3 abr. 2019.

GODOY, Miguel Gualano. Devolver a constituição ao povo: crítica à supremacia judicial e diálogos institucionais. Belo Horizonte: Forum, 2017.

KUHN, Thomas S. A estrutura das revoluções científicas. Tradução de Beatriz Vianna Boeira e Nelson Boeira. 10. ed. São Paulo: Perspectiva, 2011.

KUHN, Thomas S. O caminho desde a estrutura. Tradução de Cesar Mortari. São Paulo: UNESP, 2006.

LEITE, Carina Lellis Nicoll Simões. As audiências públicas no STF: mero instrumento de legitimação formal? In: SARMENTO, Daniel (coord.). Jurisdição constitucional e política. Rio de Janeiro: Forense, 2015.

RAIS, Diogo. A sociedade e o Supremo Tribunal Federal: o caso das audiências públicas. Belo Horizonte: Fórum, 2012.

VESTENA, Carolina Alves. Participação ou formalismo? O impacto das audiências públicas no Supremo Tribunal Federal brasileiro. Orientador: Guilherme 
Leite Gonçalves. 2010. 110 f. Dissertação (Mestrado Profissional em Poder Judiciário) - Escola de Direito do Rio de Janeiro da Fundação Getúlio Vargas, Rio de Janeiro, 2010. Disponível em: http://hdl.handle.net/10438/7832. Acesso em: 7 fev. 2019.

Data da submissão: 14/10/2019

Data da primeira avaliação: 08/11/2019

Data da segunda avaliação: 14/11/2019

Data da aprovação: 23/11/2019 